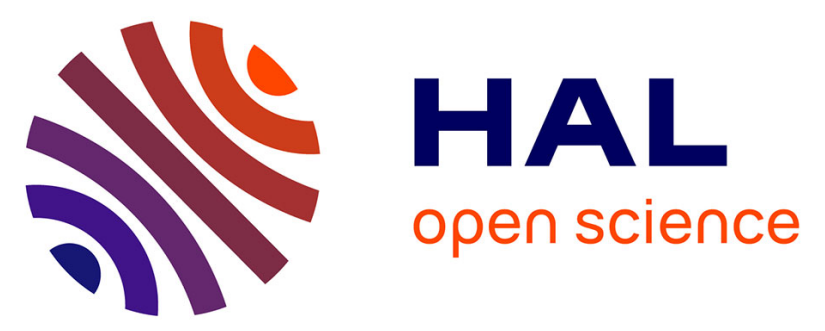

\title{
STUDY OF VERTICAL TRANSPORT IN A SUPERLATTICE GaAs/AlAs BY TIME-RESOLVED PHOTOLUMINESCENCE
}

J. Benhlal, P. Lavallard, C. Gourdon, R. Grousson, M. Roblin, A. Pougnet, R. Planel

\section{To cite this version:}

J. Benhlal, P. Lavallard, C. Gourdon, R. Grousson, M. Roblin, et al.. STUDY OF VERTICAL TRANSPORT IN A SUPERLATTICE GaAs/AlAs BY TIME-RESOLVED PHOTOLUMINESCENCE. Journal de Physique Colloques, 1987, 48 (C5), pp.C5-471-C5-474. 10.1051/jphyscol:1987599 . jpa-00226803

\section{HAL Id: jpa-00226803 https://hal.science/jpa-00226803}

Submitted on 1 Jan 1987

HAL is a multi-disciplinary open access archive for the deposit and dissemination of scientific research documents, whether they are published or not. The documents may come from teaching and research institutions in France or abroad, or from public or private research centers.
L'archive ouverte pluridisciplinaire HAL, est destinée au dépôt et à la diffusion de documents scientifiques de niveau recherche, publiés ou non, émanant des établissements d'enseignement et de recherche français ou étrangers, des laboratoires publics ou privés. 


\title{
STUDY OF VERTICAL TRANSPORT IN A SUPERLATTICE GaAs/AIAS BY TIME-RESOLVED PHOTOLUMINESCENCE
}

\author{
J. BENHLAL, P. LAVALLARD, C. GOURDON, R. GROUSSON, M.L. ROBLIN, \\ A.M. POUGNET ${ }^{*}$ and R. PLANEL ${ }^{*}$ \\ Groupe de physique des Solides de I'ENS, Université Paris \\ VII, T-23, 2, Place Jussieu, F-7525I Paris Cedex 05, France \\ * Groupement Scientifique CNET-CNRS, 196, Rue Henri Ravera, \\ F-92220 Bagneux, France
}

\begin{abstract}
RESUME : En mesurant le comportement temporel de la luminescence d'un puits quantique en fonction de l'épaisseur du super-réseau qui le sépare de la surface de l'échantilion, nous déterminons le coefficient de diffusion dans le super-réseau. Nous montrons que les excitations qui diffusent sont des excitons du super-réseau.
\end{abstract}

ABSTRACT : By measuring the luminescence time behaviour of an enlarged quantum well as a function of the superlattice thickness, we determine the diffusion coefficient in the superlattice. We show that very likely the excitations which diffuse are excitons.

\section{I - INTRODUCTION}

Deveaud et al [1] have studied the time behaviour of the luminescence of a $40 \AA$ GaAs - $40 \AA$ GaAlAs superlattice (S.L.) with one enlarged well (Q.W.) 0.9 um away from the surface. The well width is $54 \AA$. Their experiment is very comparable to the one performed by Göbel et al $\{2 \mid$ excepted that the surface layer is not GaAlAs but a superlattice. They used a four-level model to describe their results. Many parameters have to be taken into account. Furthermore the diffusion process is only described by a characteristic time.

In this paper we present results obtained on a $36 \AA \mathrm{GaAs}$ Q.W. in a $18 \AA \mathrm{GaAs}-9$ $\AA$ AlAs S.L. The investigated sample was grown in a molecular-beam-epitaxy reactor at $680^{\circ} \mathrm{C}$ on GaAs substrate. $\mathrm{R}-\mathrm{X}$ ray diffraction have been performed. The total thickness of the S.L. is $6 \mu \mathrm{m}$. The Q.W. lies in the middle of it. The sample was wedgeshaped by chemical polish (1 $\mu \mathrm{m}$ per $\mathrm{mm})$. Then depending on the position along the direction of the wedge, the enlarged well is situated at different depths from the surface, from $\ell=0 \mu \mathrm{m}$ to $\ell=3 \mu \mathrm{m}$.

The time behaviour of the Q.W. luminescence is studied for different thicknesses of the S.L. before the Q.W. and for different absorption coefficients of exciting light. The results are explained by a diffusion model of photo-excited states in the S.L.

\section{II - EXPERIMENTS}

The light source is a dye laser (D.C.M.) pumped synchronously by a mode-locked $\mathrm{Ar}^{+}$laser. The luminescence light of the sample immersed in pumped liquid helium passes through two spectometers put in a substractive way. A streak camera working in the synchro-scan mode allows us to record the time behaviour of luminescence with a time resolution of 30 ps. Figure 1 shows the time behaviour of the luminescence of the $Q . W$. for $\ell=3 \mu \mathrm{m}$. The curves obtained for others depths are very similar. The wavelength of the exciting light is $655 \mathrm{~nm}$ and the absorption coefficient is weak. (We checked it by recording the excitation spectrum of the S.L.) 


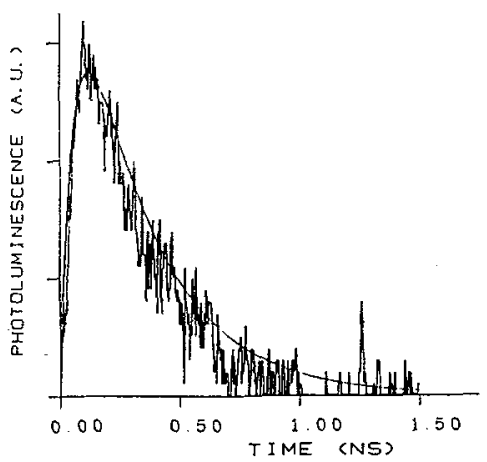

Figure 1 : Q.W. Iuminescence intensity versus time. The excitation wavelength is $655 \mathrm{~nm}$. The Q.W. is at $3 \mathrm{um}$ from the surface. The fit is made with a three-level model $\left(\tau_{\mathrm{w}}=60 \mathrm{ps}, \tau_{\mathrm{SL}}=300 \mathrm{ps}\right)$

Figure 2 shows the time behaviour of the luminescence of the Q.W. for two different depths $h=0.45 \mu \mathrm{m}$ and $\ell=3 \mu \mathrm{m}$. The wavelength of the exciting light is $620 \mathrm{~nm}$ and the absorption coefficient is high. Now, the two curves are different. The maximum of the 3 m-curve is delayed by about 300 ps with respect to the maximum of the 0.45 um-curve. Its decay is slower.

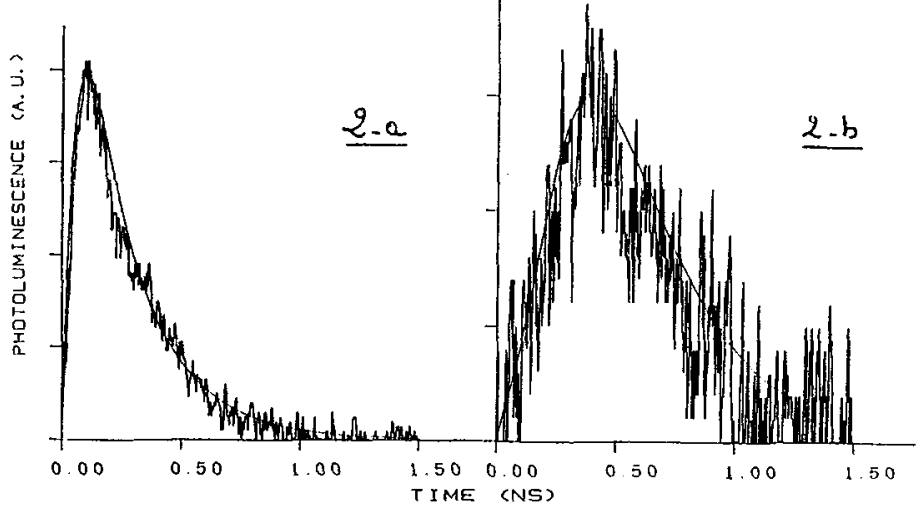

Figure 2 : Q.W. luminescence intensity versus time. The excitation wavelength is 620 nm.
a) $\ell=0.45 \mu \mathrm{m}$
b) $=l=3 \mu \mathrm{m}$

The two curves are fitted with the diffusion model $\left(\tau_{\mathrm{w}}=60 \mathrm{ps}, \tau_{\mathrm{SL}}=300 \mathrm{ps}, \alpha=\right.$ $20000 \mathrm{~cm}^{-1}, \mathrm{D}=30 \mathrm{~cm}^{2} \cdot \mathrm{s}^{-1}$ ).

\section{III - THEORY}

We assume a one-dimension diffusion equation for the excited states in the S.L.

$$
\frac{\partial n_{S L}}{\partial t}=D \frac{\partial^{2} n_{S L}}{\partial x^{2}}-\frac{n_{S L}}{\tau_{S L}}
$$

${ }^{n} S_{L}$ is the one dimension density of excited states in the S.L. ; D is the diffusion coefficient and $\tau_{\mathrm{SL}}$ the lifetime.

The Q.W. is assumed to act only as a probe without modifying the diffusion in the S.L.

The number of excitons created in the Q.W. $N_{W}$ is obtained by the following equation :

$$
\frac{\mathrm{dN}_{\mathrm{w}}}{\mathrm{dt}}=\left.\Delta \ell \cdot \frac{\mathrm{n} S \mathrm{SL}}{\tau_{\mathrm{T}}}\right|_{\mathrm{x}=\ell}-\frac{\mathrm{N}_{\mathrm{w}}}{\tau_{\mathrm{w}}}
$$


The value of $n_{S L}$ is taken at the depth $x=l$ where the Q.W. is located; $\tau_{w}$ is the lifetime of excited states in the Q.W. ; ${ }^{\tau} T$ is the trapping time of excited states of the S.L. and $\Delta l$ is the Q.W. width.

We looked for the solution of the diffusion equation [3] with the following boundary conditions :

$\left.\frac{\partial n_{S L}}{\partial x}\right|_{x=0}=0$

surface recombination equal to zero

$n_{S L}(x=d, t)=0$

infinite recombination velocity on the superlattice-substrate interface.

$\mathrm{n}_{S L}(\mathrm{x}, 0)=\alpha \mathrm{N} \exp (-\alpha \mathrm{x})$

$\alpha$ is the absorption coefficient of light and $N$ the number of photoexcited states. The number of excitons in the Q.W. is :

$N_{w}(t)=\sum_{m=0}^{\infty} \alpha N \frac{\Delta \ell}{d} c_{m} \cos \left(\lambda_{m} l\right) \frac{1}{\tau_{T}} \int_{0}^{t} e^{-\lambda^{2}} D t^{\prime} e^{-t^{\prime} / \tau} S L \frac{\left(t^{\prime}-t\right)}{\tau_{w}} d t^{\prime}$

The parameters $\lambda_{\mathrm{m}}$ and $\mathrm{C}_{\mathrm{m}}$ are determined by the boundary conditions.

When the absorption coefficient of light is weak, diffusion process does not play a big role. Figure 1 shows the theoretical fit with a three-level model. We determine then the two times $\tau_{w}=60$ ps and $\tau_{S L}=300$ ps.

When the absorption coefficient is high, we take into account the diffusion. We keep the previous determinations of the lifetimes and look for the best fit when varying the diffusion coefficient value. Figure 2 shows the result for $D=30 \mathrm{~cm}^{2} \cdot \mathrm{s}^{-1}$.

\section{IV - DISCUSSION}

1 - The diffusion coefficient value we found is rather high for a low temperature process. Though excitonic temperature may be much larger than the lattice temperature. On the other hand, we made the assumption that the Q.W. does not disturb the diffusion in the S.L. i.e. :

$$
\left.\frac{\frac{\partial^{2} n_{S L}}{\partial x^{2}}}{n_{S L}}\right|_{x=\ell} \gg \frac{1}{\tau_{T}}
$$

This assumption is rather bad for $\ell=3 \mu \mathrm{m}$. The consequence is that the diffusion coefficient value we determine is overestimated.

2 - We did not discuss until now the nature of the excitation which diffuses in the S.L. Because they observed in the Q.W. excitation spectrum small antiresonances at the maxima of absorption corresponding to heavy and light exciton creations Lambert et al 14 | claimed that S.L. excitons are not efficient to populate the $\dot{Q} . W$. We observed too these structures. They are indeed well explained in the exciton diffusion model. Figure 3 shows the Q.W. luminescence intensity as a fonction of the absorption coefficient for $\ell=3 \mu \mathrm{m}$. The curve reaches a maximum for a value of $\alpha \simeq$ $5000 \mathrm{~cm}^{-1}$ and then decreases. Thus increasing the absorption coefficient to values higher than the value at maximum decreases the intensity of luminescence : the absorption maxima correspond to antiresonances in the Q.W. excitation spectrum. 


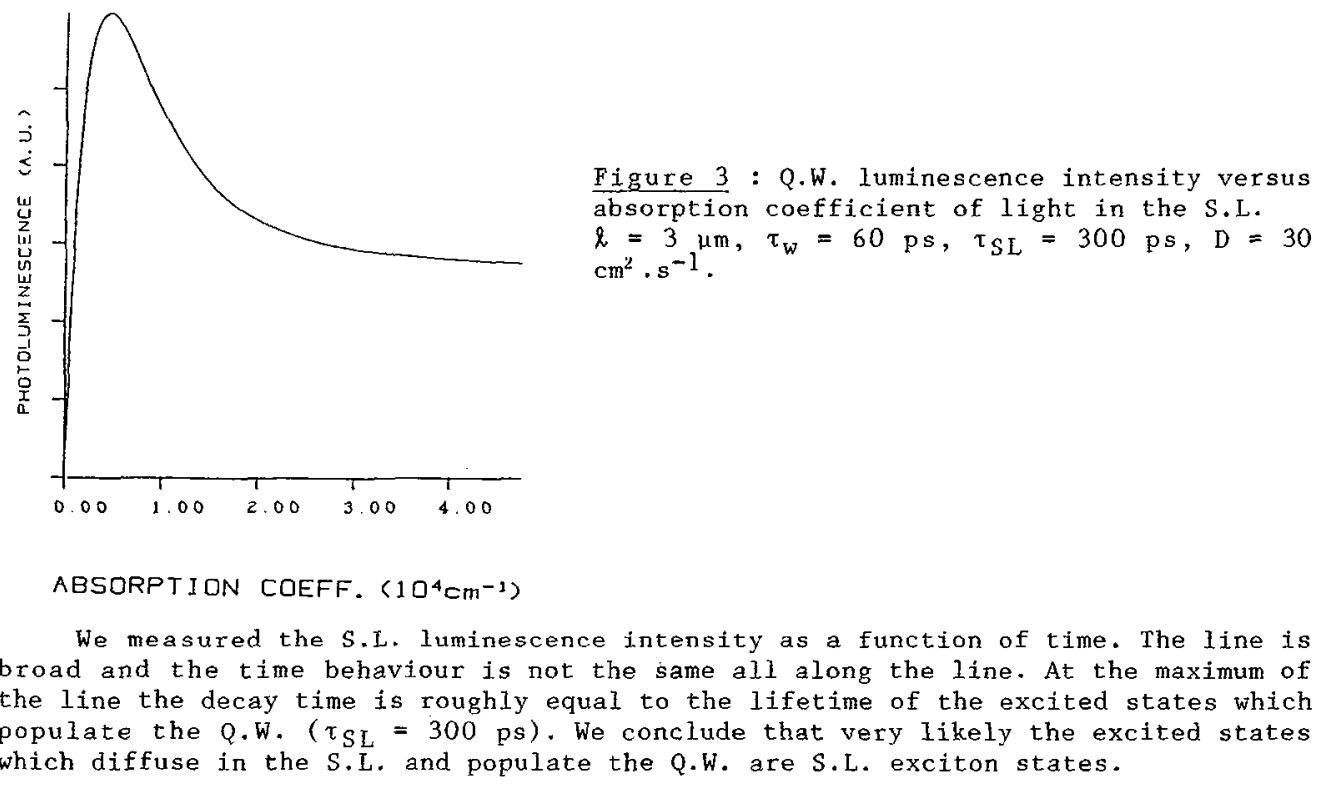

Figure 3 : Q.W. Iuminescence intensity versus absorption coefficient of light in the S.L. $l=3 \mu \mathrm{m}, \tau_{\mathrm{w}}=60 \mathrm{ps}, \tau_{S L}=300 \mathrm{ps}, \mathrm{D}=30$ $\mathrm{cm}^{2} \cdot \mathrm{s}^{-1}$.

\section{REFERENCES}

11] B. DEVEAUd, A. CHOMETTE, R. LAMBERT, A. REGRENY, R. ROMESTAIN and P. EDEL, Sol. St. Comm. 57 (1986) 885.

12 G.O. GÖBEL, J. KUHL and R. HÖGER, J. Lum. 30 (1985) 541.

[3] Y. ADDA and J. PHILIBERT, "La diffusion dans les solides", Presses Universitaires de France, Paris (1966) Tome I.

14] R. LAMBERT, R. ROMESTAIN, D. MILlER, A. CHOMETTE, A. REgRENY and B. DEVEAUD, Proc. 15th Int. Conf. on GaAs and related compounds, Biarritz, the Institute of Physics. Conference Séries $n^{\circ} 74$ (1984) 357. 